Volume 2 Nomor 1 Januari 2022: Halaman: 20- 25

Doi: $10.47650 /$ pjphsr.v2i1.312

ISSN (Online): 2777-1296

OJS: http://journal.unpacti.ac.id/index.php/pjphsr

\title{
FACTORS AFFECTING NURSE DISCIPLINE AT LABUANG BAJI HOSPITAL, MAKASSAR CITY
}

Faktor-faktor Yang Mempengaruhi Kedisiplinan Perawat di RSUD Labuang Baji Kota Makassar

Asrianto*, Riska Wardana

Program Studi IImu Keperawatan Sekolah Tinggi Ilmu Kesehatan Yapika, Makassar, Indonesia

*Alamat Korespondensi: asriantoazis@yahoo.com

\section{Article Info}

Article History

Received: 05 Des 2021

Revised : 12 Des 2021

Accepted : 16 Des 2021

\section{Keywords :}

Discipline,

Personality,

Environment

\section{Kata kunci :}

Kedisiplinan,

Kepribadian,

Lingkungan

\begin{abstract}
ABSTRAK
Discipline is something that becomes a benchmark to find out whether the role of a manager or leader as a whole can be carried out properly or not. Discipline is also a form of nurses' self-control and regular implementation in showing the level of seriousness of nurses' work in a hospital, where nurses who do not comply with the regulations set by the hospital will get sanctions. Therefore, this disciplinary action cannot be applied arbitrarily, so it requires wise consideration. This study aims to determine the level of discipline of nurses at Labuang Baji Hospital, Makassar City. This research is a quantitative research with a cross sectional approach. The research has been carried out at the Labuang Baji Hospital, Makassar City with a sample of 50 respondents (nurses). Samples were taken using a non-random sampling method with inclusion and exclusion criteria set by the researcher. Data collection was done by using a questionnaire. Data analysis with chi-square test consisted of univariate and bivariate analysis. The results of the univariate analysis showed that more than $80 \%$ of the respondents had good personality, environmental and discipline factors and the results of the Bivariate analysis showed that there was no influence between personality and environmental factors on the discipline of nurses at Labuang Baji Hospital Makassar with a $P$ value> 0.599 . The results of this study are expected to be used as reference material for learning about nurse discipline and it is hoped that health workers will use this research as input for carrying out their duties.
\end{abstract}

Kedisiplinan merupakan suatu hal yang menjadi tolak ukur untuk mengetahui apakah peran seorang manajer atau pimpinan secara keseluruhan dapat dilaksanakan dengan baik atau tidak. Disiplin juga merupakan bentuk dari pengendalian diri perawat dan pelaksanaan yang teratur dalam menunjukkan tingkat kesungguhan kerja perawat pada suatu Rumah Sakit, dimana para perawat yang tidak mematuhi peraturan yang telah ditetapkan Rumah Sakit akan mendapatkan sanksi. Oleh karena itu tindakan disiplin ini tidak bisa diterapkan secara sembarangan, sehingga memerlukan pertimbangan yang bijak. Penelitian ini bertujuan untuk mengetahui tingkat kedisiplinan perawat RSUD Labuang Baji kota Makassar. Penelitian ini merupakan penelitian kuantitatif dengan pendekatan cross sectional. Penelitian telah dilaksanakan di RSUD labuang Baji Kota Makassar dengan jumlah sampel 50 responden (perawat). Sampel diambil dengan menggunakan metode non random sampling dengan kriteria inklusi dan eksklusi yang ditetapkan peneliti. Pengambilan data dilakukan dengan menggunakan kuesioner. Analisis data dengan uji chi-square terdiri dari analisis univariat dan bivariat. Hasil analisis univariat menunjukkan bahwa lebih dari $80 \%$ responden memiliki faktor kepribadian, lingkungan dan kedisiplinan yang baik dan hasil analisis Bivariat menunjukkan bahwa tidak ada pengaruh antara faktor kepribadian dan lingkungan terhadap kedisiplinan perawat di RSUD Labuang Baji kota Makassar dengan nilai $P>0,599$. Hasil penelitian ini diharapkan dapat dijadikan bahan acuan untuk belajar tentang kedisiplinan perawat dan diharapkan bagi petugas kesehatan agar penelitian ini dijadikan bahan masukan untuk menjalankan tugasnya. 


\section{PENDAHULUAN}

World Health Organization (WHO) atau Badan Kesehatan Dunia 2017, bahwa dalam rangka peningkatan kinerja perawat baik dalam penegakan disiplin terhadap perawat harus dapat memberikan kenyamanan maupun kepuasan terhadap perawat sebagai apresiasi atas kinerja yang mereka jalani.

Peraturan Menteri Kesehatan Republik Indonesia Nomor 38 tahun 2018, bahwa untuk mendukung optimalisasi pelaksanaan tri dharma perguruan tinggi pada politeknik kesehatan dilingkungan Badan Pengembangan dan Pemberdayaan Sumber Daya Manusia Kesehatan Kementerian Kesehatan, perlu adanya upaya peningkatan dan pengembangan penyelengaraan pendidikan tinggi di bidang kesehatan yang dilaksanakan secara berkesinambungan.

Kedisiplinan merupakan suatu hal yang menjadi tolak ukur untuk mengetahui apakah peran seorang manajer atau pimpinan secara keseluruhan dapat dilaksanakan dengan baik atau tidak. Keperawatan adalah salah satu profesi di Rumah sakit maupun di Puskesmas yang berperan penting dalam penyelenggaraan upaya menjaga mutu pelayanan kesehatan di Puskesmas maupun Rumah Sakit. Pelayanan kesehatan di Puskesmas merupakan bentuk pelayanan di berikan kepada klien, oleh suatu tim multi disiplin termasuk tim keperawatan. Tim keperawatan merupakan anggota tim kesehatan yang menghadapi masalah kesehatan klien selama 24 jam secara terus menerus (Yeni, 2017).

Pembangunan kesehatan diarahkan untuk mewujudkan derajat kesehatan yang dioptimalkan untuk mencapai tujuan tersebut di butuhkan upaya pengolaan berbagai sumber daya manusia (Adelina, 2018). Kinerja dalam suatu organisasi dilakukan oleh segenap sumber daya manusia yang ada, baik pimpinan maupun pekerja. Ada beberapa faktor yang dapat mempengaruhi sumber daya manusia dalam menjalankan kinerjanya salah satunya yang juga harus di perhatikan adalah disiplin kerja (Ginting \& Wau, 2019). Hasibuan dalam (Amin, Sari, \&
Rachmad, 2019) menyatakan ada beberapa faktor yang berhubungan dengan disiplin kerja diantaranya yaitu tujuan dan kemampuan, keteladanan pemimpin, balas jasa, keadilan, pengawasan, sanksi hukuman, ketegasan dan hubungan kemanusiaan.

Pusat kesehatan masyarakat (Puskesmas) merupakan fasilitas pelayanan kesehatan yang menyelenggarakan upaya kesehatan dan upaya kesehatan perorangan tingkat pertama, dengan lebih mengutamakan upaya promotif dan preventif, untuk mencapai derajat kesehatan masyarakat yang setinggi-tingginya di wilayah kerjanya (Lengkong, Rumayar, \& Maramis, 2018). Kualitas merupakan tingkat sejauh mana proses atau hasil pelaksanaan kegiatan mendekati kesempurnaan atau mendekati tujuan yang diharapkan. Bila persyaratan atau spesifikasinya terpenuhi berarti kualitas yang dimaksud dapat dikatakan baik, sebaliknya jika persyaratan itu tidak terpenuhi maka dapat dikatakan tidak baik (Widianti, Noor, \& Linggi, 2018).

Produktivitas pegawai, saat ini menjadi pusat perhatian dalam upayanya untuk meningkatkan kinerja yang mengkonsentrasikan pada kinerja, akan lebih memberikan penekanan pada faktor utama antara lain adalah motivasi kerja pegawai (Gustin, Putra, \& Delita, 2017). Motivasi adalah serangkaian sikap dan nilai-nilai yang mempengaruhi individu untuk mencapai hal yang spesifik sesuai dengan tujuan individu (Ifiani \& Kurniawat, 2017). Dampak dari motivasi kerja pegawai yang rendah adalah disiplin kerja yang juga rendah seperti keterlambatan pegawai datang di tempat kerja, kurang bertanggungjawabnya pegawai terhadap pekerjaan, tidak tercapainya program-program puskesmas dan sebagainya (Kasim \& Ginting, 2019).

Dalam menghasilkan kinerja perawat yang optimal dibutuhkan disiplin kerja agar tujuan organisasi dapat tercapai. Menurut Ardana, Mujiati dan utama (2012: 134) disiplin kerja adalah suatu sikap menghormati, menghargai, patuh dan taat terhadap peraturan-peraturan 
yang berlaku, baik yang tertulis maupun yang tidak tertulis serta sanggup menjalankannya dan tidak mengelak untuk menerima sanksi-sanksinya. Disiplin kerja juga manajemen sumber daya manusia yang terpenting, karena semakin baik disiplin kerja perawat semakin tinggi juga prestasi kerja yang akan di capai. Disiplin kerja tidak hanya bermanfaat bagi perawat karena dapat meningkatkan semangat kerja perawat (Tyas, 2018).

Kedisiplinan merupakan suatu hal yang menjadi tolak ukur untuk mengetahui apakah peran seorang manajer atau pimpinan secara keseluruhan dapat dilaksanakan dengan baik atau tidak. Disiplin juga merupakan bentuk dari pengendalian diri perawat dan pelaksanaan yang teratur dalam menunjukkan tingkat kesungguhan kerja perawat pada suatu Puskesmas, di mana para perawat yang tidak mematuhi peraturan yang telah di tetapkan Puskesmas akan mendapatkan sanksi. Oleh karena itu tindakan disiplin ini tidak bisa di terapkan secara sembarangan, sehingga memerlukan pertimbangan yang bijak ( Nawawi, 2015).

Disiplin kerja adalah proses perkembangan konstruktif bagi pegawai yang berkepentingan karena disiplin kerja di tunjukkan pada tindakan bukan orangnya. Disiplin juga sebagai proses pada pegawai agar pegawai dapat mengembangkan kontrol diri dan agar dapat menjadi lebih efektif dalam bekerja. Dengan demikian tindakan pendisiplinan juga hendaknya mempunyai sasaran yang positif, bersifatnya mendidik, dan mengoreksi bukan tindakan negatif yang menjatuhkan pegawai atau bawaan yang indisipliner (Bintoro dan Daryanto, 2017).

Menurut PPNI (Persatuan Perawat Nasional Indonesia) di Makassar, fenomena yang terjadi saat ini menyangkut perawat yaitu seringkali terjadi ketidakseimbangan insentif atau reward antara kelompok dokter, perawat dan yang setara dengan perawat, tenaga administrasi serta tingkatan manajer Rumah sakit sehingga menyebabkan menurunnya komitmen karyawan terhadap organisasi khususnya perawat. Dengan menurunnya komitmen tersebut, maka kinerja perawat pun menjadi menurun atau kurang. Hal inilah yang sangat mempengaruhi kinerja perawat di suatu Rumah sakit, di samping faktor-faktor lain yang mungkin mendukung penurunan kinerja perawat di Makassar (PPNI Makassar, 2012).

Oleh sebab itu, bersumber pada penjelasan latar belakang diatas hingga peneliti tertarik melaksanakan penelitian mengenai“ Faktor- faktor yang mempengaruhi kedisiplinan perawat di Rumah Sakit Umum Daerah Labuang Baji Kota Makassar".

\section{BAHAN DAN METODE}

Design penelitian yang digunakan adalah penelitian kuantitatif, dengan pendekatan cross sectional. Populasi sebanyak 200 orang perawat dimana sampel penelitian yang memenuhi syarat kriteria inklusi sebanyak 50 perawat (responden). Teknik pengambilan data pada penelitian ini menggunakan data primer dan sekunder.

\section{HASIL}

Tabel 1. Karakteristik Responden

\begin{tabular}{lcc}
\hline \multirow{2}{*}{ Karakteristik } & \multicolumn{2}{c}{ Responden } \\
\cline { 2 - 3 } & $\mathbf{n}$ & $\mathbf{\%}$ \\
\hline Jenis Kelamin & & \\
$\quad$ Laki-laki & 6 & 12,0 \\
$\quad$ Perempuan & 44 & 88,0 \\
Umur (tahun) & & \\
$\quad 20-40$ & 20 & 40,0 \\
$\quad 41-60$ & 30 & 60,0 \\
Pendidikan & & \\
$\quad$ D3 & 5 & 10,0 \\
$\quad$ S1 & 21 & 42,0 \\
$\quad$ Ners & 24 & 48,0 \\
Masa Kerja (tahun) & & \\
$\quad<10$ & 25 & 50,0 \\
\hline > 10 & 25 & 50,0 \\
Status Kepegawaian & & \\
$\quad$ PNS & 35 & 70,0 \\
\hline Non PNS & 15 & 30,0 \\
\hline \multicolumn{1}{c}{ Total } & $\mathbf{5 0}$ & $\mathbf{1 0 0 , 0}$ \\
\hline
\end{tabular}

Sumber: Data Primer 2021 
Tabel 1 menunjukkan bahwa karakteristik responden berdasarkan jenis kelamin yang tertinggi adalah perempuan sebanyak 44 (88.0\%) responden dan yang terendah adalah Laki-laki sebanyak 6 (12.0\%) Responden. Berdasarkan umur, responden terbanyak merupakan responden dengan kelompok umur 41-60 tahun sebanyak 30 orang (60.0\%) dan terendah adalah umur $20-40$ tahun sebanyak 20 orang ( $40.0 \%$ ) responden.

Berdasarkan tingkat pendidikan responden, mayoritas responden dengan tingkat pendidikan Ners yaitu sebanyak 24 (48.0\%) responden dan paling sedikit merupakan responden dengan tingkat pendidikan D3 yaitu sebanyak 5 (10.0\%) responden. Sedangkan berdasarkan masa kerja, responden dengan masa kerja $<10$ tahun sebanyak 25 (50.0\%) responden dan $>10$ tahun sebanyak 25 (50.0\%) responden. Dan yang berstatus kepegawaian sebagai PNS sebanyak 35 (70.0\%) responden dan NON PNS sebanyak 15 (30.0\%) responden (tabel 1).

Tabel 2 menunjukkan bahwa berdasarkan faktor kepribadian perawat, umumnya perawat memiliki kepribadian yang baik yaitu sebanyak 42 $(84,0 \%)$ responden dan yang kurang baik sebanyak
$8(16,0 \%)$ responden. Sama halnya dengan dengan faktor lingkungan, terdapat $42(84.0 \%)$ responden yang menjawab Baik dan 8 (16.0\%) responden yang menjawab Kurang Baik. Sedangkan berdasarkan kedisiplinan perawat, mayoritas perawat memiliki kedisiplinan baik yaitu sebanyak 45 (90.0\%) responden, sedangkan yang memiliki kedisiplinan kurang baik sebanyak 5 (10.0\%) responden.

Tabel 2. Gambaran Faktor Kepribadian, Lingkungan dan Kedisiplinan Perawat di RSUD Labuang Baji Kota Makassar

\begin{tabular}{lcc}
\hline \multirow{2}{*}{ Variabel } & \multicolumn{2}{c}{ Responden } \\
\cline { 2 - 3 } & $\mathbf{n}$ & $\%$ \\
\hline Faktor Kepribadian & & \\
$\quad$ Baik & 42 & 84,0 \\
$\quad$ Kurang Baik & 8 & 16,0 \\
\hline $\begin{array}{l}\text { Faktor Lingkungan } \\
\quad \text { Baik }\end{array}$ & 42 & 84,0 \\
$\quad$ Kurang Baik & 8 & 16,0 \\
\hline Kedisiplinan Perawat & & \\
$\quad$ Baik & 45 & 90,0 \\
$\quad$ Kurang Baik & 5 & 10,0 \\
\hline$\quad$ Total & $\mathbf{5 0}$ & $\mathbf{1 0 0 , 0}$ \\
\hline
\end{tabular}

Sumber: Data Primer 2021

Tabel 2 . Hubungan Faktor Kepribadian dan Faktor Lingkungan dengan Kedisplinan Perawat di RSUD Labuang Baji Kota Makassar

\begin{tabular}{|c|c|c|c|c|c|c|}
\hline \multirow{3}{*}{ Variabel } & \multicolumn{4}{|c|}{ Kedisiplinan } & \multirow{3}{*}{ Jumlah } & \multirow{3}{*}{$P$ value } \\
\hline & \multicolumn{2}{|c|}{ Baik } & \multicolumn{2}{|c|}{ Kurang Baik } & & \\
\hline & $\mathrm{n}$ & $\%$ & $\mathbf{n}$ & $\%$ & & \\
\hline \multicolumn{6}{|l|}{ Faktor Kepribadian } & \multirow{3}{*}{0,559} \\
\hline Baik & 38 & 90,5 & 4 & 9,5 & 42 & \\
\hline Kurang Baik & 7 & 87,5 & 1 & 12,5 & 8 & \\
\hline \multicolumn{6}{|l|}{ Faktor Lingkungan } & \multirow{3}{*}{0,559} \\
\hline Baik & 38 & 90,5 & 4 & 9,5 & 42 & \\
\hline Kurang Baik & 7 & 87,5 & 1 & 12,5 & 8 & \\
\hline
\end{tabular}

Tabel 2 menunjukkan bahwa faktor kepribadian baik yang memiliki kedisiplinan baik sebanyak 38 responden dan faktor kepribadian kurang baik yang memiliki kedisiplinan kurang baik sebanyak 1 responden. Nilai $\mathrm{p}$ value diperoleh dari uji statistik yaitu 0,599 >0,05. Hal ini menunjukkan bahwa tidak ada pengaruh antara faktor kepribadian terhadap kedisiplinan perawat di RSUD Labuang Baji Kota Makassar.

Hasil yang sama juga diperoleh pada faktor lingkungan. Penelitian ini menemukan bahwa faktor lingkungan baik yang memiliki kedisiplinan baik sebanyak 38 responden dan faktor lingkungan kurang baik yang memiliki kedisiplinan 
kurang baik sebanyak 1 responden. . Nilai p value diperoleh dari uji statistik yaitu 0,599 $>0,05$. Hal ini menunjukkan bahwa tidak ada pengaruh antara faktor lingkungan terhadap kedisiplinan perawat di RSUD Labuang Baji Kota Makassar.

\section{PEMBAHASAN}

\section{Faktor yang Mempengaruhi Kedisiplinan Perawat}

Penelitian ini dilakukan dengan memberikan kuesioner sesuai dengan faktorfaktor yang telah diteliti yaitu faktor kepribadian dan faktor lingkungan. Untuk mengetahui signifikasi faktor-faktor yang mempengaruhi kedisiplinan perawat maka dilakukan analisis data dengan uji statistik menggunakan uji chi-square. Hasil crosstab faktor-faktor yang mempengaruhi kedisiplinan perawat, jika nilai asymp.sig (2-sided) $<0,05$ maka artinya HO di tolak dan Ha diterima jika nilai Asymp.sig (2-sided) > 0,05 maka artinya HO diterima dan Ha ditolak.

\section{Faktor Kepribadian}

Faktor yang penting dalam diri keperibadian seseorang adalah sistem nilai yang dianut, sistem nilai dalam hal ini yang berkaitan langsung dengan disiplin. Nilai-nilai yang menjunjung disiplin yang diajarkan atau ditanamkan orang tua, guru, dan masyarakat akan digunakan sebagai kerangka acuan bagi penerapan disiplin di tempat kerja. Sistem nilai ini akan terlihat dari sikap seseorang dan sikap diharapkan akan tercermin dalam perilaku.

Hasil analisis faktor keperibadian terhadap kedisiplinan perawat di RSUD Labuang Baji Kota Makassar setelah dilakukan analisis data dengan uji statistik menggunakan uji chi-square menunjukkan nilai tidak signifikan 0,599 > 0,05 yang artinya Ha ditolak dan HO diterima. Hal ini menunjukkan bahwa faktor kepribadian terhadap kedisiplinan tidak ada pengaruh.

Penelitian ini sejalan dengan penelitian yang dilakukan oleh Dewi Purnama dan putranto Manalu, 2020) "Hubungan sanksi dengan tingkat kedisiplinan tenaga kerja di puskesmas Padang
Bulan Kota Medan", juga menyebutkan bahwa variabel pendidikan tidak memiliki hubungan yang bermakna dengan kinerja seseorang. Setelah dilakukan uji chi-squre, diketahui bahwa nilai $\mathrm{p}$ value >a $(0,05)$, hal tersebut menunjukkan bahwa tidak terdapat hubungan yang bermakna antara hubungan sanksi dengan tingkat kedisiplinan tenaga kerja di wilayah kerja Puskesmas Padang Bulan Kota Medan. Hal tersebut sejalan dengan yang di sampaikan oleh (Qatmeemalmarhoon, Mohdnoor, Abdalla, \& Musbah, 2017) bahwa tidak hubungan yang bermakna antara motivasi kerja terhadap karyawan. Penelitian lain yang sejalan yaitu fachri (2010) yang menyatakan bahwa tidak adanya hubungan yang signifikan antara tujuan dengan disiplin kerja.

Dengan begitu dapat disimpulkan bahwa faktor kepribadian tidak ada pengaruh terhadap kedisiplinan perawat di RSUD Labuang Baji Makassar.

\section{Faktor Lingkungan}

Upaya menanamkan kedisiplinan pada dasarnya adalah menanamkan nilai-nilai guna mencapai tujuan Rumah Sakit. Berdasarkan pernyataan-pernyataan diatas, dapat ditarik kesimpulan bahwa faktor-faktor yang mempengaruhi kedisiplinan perawat adalah faktor-faktor dari luar individu yaitu kepemimpinan, peranan yang berlaku di lingkungan kerja serta faktor dari dalam yaitu moral atau semangat dan kesadaran dari perawat akan pentingnya disiplin kerja, disiplin karena kepatuhan akan komitmen yang ada dan kepatuhan yang didasarkan pada identifikasi.

Hasil analisis faktor lingkungan terhadap kedisiplinan perawat di RSUD Labuang Baji Makassar setelah dilakukan analisis data dengan uji statistik menggunakan uji chi-square menunjukkan nilai tidak signifikan 0,599 > 0,05 yang artinya $\mathrm{Ha}$ ditolak dan $\mathrm{HO}$ diterima, hal ini menunjukkan bahwa hal ini menunjukkan bahwa faktor kepribadian terhadap kedisiplinan tidak ada pengaruh.

Penelitian ini sejalan dengan penelitian yang dilakukan oleh Sari Hijayanti "Pengaruh 
Disiplin Kerja Terhadap Kinerja Perawat Di Rumah Sakit Dustra Cimahi, Jawa Barat" yang menganalisis pengaruh lingkungan kerja terhadap kinerja karyawan dengan kesimpulan pengaruh positif disiplin kerja dengan kinerja ditolak karena diperoleh nilai signifikan sebesar 0,102. Hasil analisis dengan menggunakan chi-square diperoleh nilai $p$ value $=0,332$ atau nilai $p>0,05$. Dengan demikian maka HO diterima dan Ha ditolak sehingga dapat disimpulkan bahwa tidak ada hubungan yng bermakna antara disiplin kerja dengan kinerja perawat di Rumah Sakit Dustra Cimahi, Jawa Barat.

Dengan begitu dapat disimpulkan bahwa faktor lingkungan tidak ada pengaruh terhadap kedisiplinan perawat di RSUD Labuang Baji Makassar.

\section{KESIMPULAN DAN SARAN}

Penelitian ini menyimpulkan bahwa tidak ada hubungan antara faktor kepribadian dan faktor lingkungan dengan kedisiplinan perawat di RSUD Labuang Baji Makassar.

\section{DAFTAR PUSTAKA}

Asmiarsih. (2014). e-journal. Dipetik Januari 8, 2020, dari Jenis-jenis Disiplin
Kerja:https://www.ejournal.com/2014/02/jenis-jenis-disiplinkerja.html.

Bintoro, dan Daryanto. (2017). Manajemen Penilaian Kinerja Karyawan. Yogyakarta: Gava Media.

Bugis,S. (2018). Hubungan Antara Komitmen Organisasi Dengan Disiplin Kerja Pada Anggota Lembaga Dakwah Kampus (LDK) Di Yogyakarta. Dipetik Januari 8, 2020, dari eprints.mercubuanayogya:http://eprints.m ercubuana-yogya.ac.id/id/eprint/3789.

Harahap, R. E. (2016). Hubungan Kepemimpinan Transformasional dan Disiplin Kerja Dengan Kinerja Perawat Rumah Sakit TK.Il Putri Hijau Medan. Jurnal Magister Psikologi UMA, 8.

Hasibuan, Malayu S.P.(2014). Manajemen Sumber Daya Manusia, Edisi Revisi. Jakarta:Bumi Aksara

Iskandar. (2008). Manajemen Sumber Daya Manusia Dilengkapi dengan Perilaku Organisasi dan Teori Penerapan. Bandung: Multazam.

Kasim \& Ginting, (2019). Faktor Determinan yang Berhubungan dengan Motivasi Kerja Pegawai Di Puskesmas. http://ejournal.delihusada.ac.id/index.php/J PKSY/article/view/162. 